\title{
Periodontitis as a risk factor for preterm labour and low birth weight among pregnant women attending a tertiary care teaching hospital
}

\section{Saranya Chokkaiyan $^{1}$, Sendhil Coumary Arumugam*, Saravana Kumar², Lopa B John ${ }^{1}$, Seetesh Ghose ${ }^{1}$}

\author{
${ }^{1}$ Department of Obstetrics and Gynecology, Mahatma Gandhi Medical College and Research Institute, Puducherry, \\ India \\ ${ }^{2}$ Department of Periodontology, Indira Gandhi Institute of dental Sciences, Puducherry, India
}

Received: 16 August 2015

Revised: 12 September 2015

Accepted: 27 October 2015

\section{*Correspondence:}

Dr. Sendhil Coumary Arumugam,

E-mail: sendhilcoumary1975@yahoo.in

Copyright: ( ) the author(s), publisher and licensee Medip Academy. This is an open-access article distributed under the terms of the Creative Commons Attribution Non-Commercial License, which permits unrestricted non-commercial use, distribution, and reproduction in any medium, provided the original work is properly cited.

\begin{abstract}
Background: Preterm birth is the single most important factor affecting perinatal outcome in terms of both morbidity and mortality. Chronic infections in mother are being implicated as a cause of preterm labour. The objective of this study was to find out a causal association between periodontitis and preterm labour or low birth weight. It was a CaseControl Study. This study was conducted in Mahatma Gandhi Medical College and Research Institute, Puducherry between February 2013 and June 2014.

Methods: A total of 200 women were included in the study with 100 women in each group (cases and controls). Cases included women who had spontaneous preterm labour or threatened PTL (gestational age 28- 36 weeks) or women who had delivered a baby with the birth weight being less than $2.5 \mathrm{~kg}$. Controls were patients who had a normal labour with the gestational age of more than 37 weeks with birth weight of the baby more than $2.5 \mathrm{~kg}$. Periodontal examination was done for both cases and controls. Periodontal factors like Plaque Index (PI), bleeding Index (SBI), Probing pocket depth (PD) and Clinical attachment level (CAL) were examined for both groups. Student $\mathrm{t}$ test, Chi-square and Fisher Exact has been used for statistical analysis.

Results: In the present study, plaque index and bleeding index was significantly more in cases than controls with a $\mathrm{p}$ value of 0.009 and 0.035 respectively. Evidence of periodontitis was seen in $86 \%$ of cases and $76 \%$ of controls respectively which was also statistically significant with a $\mathrm{p}$ value of 0.071 .Moderate periodontitis was found in significant number cases and was statistically significant with a $\mathrm{P}$ value of $<0.001$.

Conclusions: This suggests that there exists an association between moderate periodontitis and preterm labour and low birth weight.
\end{abstract}

Keywords: Periodontitis, Preterm labour, Low birth weight, Case-control study

\section{INTRODUCTION}

Preterm birth is the single most important factor affecting perinatal outcome in terms of both morbidity and mortality. Worldwide incidence of preterm birth is more than 1 in every 10 babies born. ${ }^{1}$ Around $60 \%$ of preterm births take place in Africa and South Asia. India leads the list of countries with the greatest number of preterm births. Preterm labour can be defined as the onset of regular uterine contractions, between the period of viability and 37 weeks of gestation associated with cervical changes. ${ }^{2}$ Preterm birth has been reported to be the leading cause of neonatal morbidity and mortality. However there has been a dramatic increase in the survival of these babies in the last decade, but about $90 \%$ of extremely premature babies die in low income countries. Prematurity also results in adverse long term consequences. Providing healthcare for these children has 
imposed a huge economic burden for both the family and country.

Among the various causes of preterm birth, $30 \%$ has been related to preterm prelabour rupture of membranes (PPROM), $45-50 \%$ of preterm births are idiopathic and another $15-20 \%$ is iatrogenic due to deliberate induction of labour for conditions compromising maternal or fetal health. ${ }^{2}$ A number of risk factors have been identified as cause of PTL. The important factors for PTL are previous preterm birth, previous second trimester pregnancy loss, trauma to the cervix and uterine over distension. Psychosocial factors, age and pre pregnancy BMI have also been implicated as causes in women with preterm labour. Infections confined to the genital tract like bacterial vaginosis can lead to PTL. Other systemic infections which result in a systemic inflammatory response like pyelonephritis and pneumonia contribute to PTL. ${ }^{2}$ Periodontal infections also promote systemic inflammatory and immune responses that may play an important role in preterm labour. ${ }^{3}$ Research was done to co-relate the levels of prostaglandin E2 (PGE2) and interleukin-1 $\beta$ (IL-1 $\beta$ ) in gingival cervicular fluid (GCF $\beta$ ) with those in amniotic fluid and it did positively corelate. ${ }^{4}$ There appears to be a two way relationship as the systemic health status of the woman will have an influence on periodontitis and vice versa. ${ }^{5}$ Also, maternal periodontitis may interact synergistically with other risk factors to induce preterm births. ${ }^{6}$

Low birth weight is defined as a birth weight lower than $2500 \mathrm{~g}$. the global prevalence of LBW is $15.5 \%$ and $96.5 \%$ of these are from developing countries. The two chief etiologies for low birth weight can be preterm birth or growth restriction. The etiology for preterm labour and low birth weight can be due to multiple factors but the series of events resulting in either are not clearly understood.

Antenatal women with periodontal disease have 2 to 3 times risk to have a preterm low-birth-weight (PLBW) baby compared to women with no periodontal infection. Women with pregnancy associated gingivitis can be screened for periodontitis and by treating these women, the rate of preterm low birth weight can be reduced. ${ }^{6}$ Periodontal treatment has significantly reduced the incidence of preterm birth and/or low birth weight in women with periodontal infection. A number of researches have investigated as to whether there is significant relationship between periodontitis and preterm labour and/or low birth weight but results have been controversial and much more research is needed to confirm its association.

The objectives of the study are to evaluate the relationship between periodontal health and the occurrence of threatened preterm labour or preterm labour and the association between maternal periodontal health and birth weight.

\section{METHODS}

The present study was conducted in Mahathma Gandhi Medical College and Research Institute, Puducherry, a tertiary care centre between February 2013 and June 2014. A total of 200 cases were studied with 100 each in case and control groups. Cases were women who had spontaneous preterm labour or threatened PTL (gestational age 28- 36 weeks) or who had delivered a baby with the birth weight being less than $2.5 \mathrm{~kg}$. Controls were patients who had a normal labour with the gestational age of more than 37 weeks and delivered a baby with birth weight more than $2.5 \mathrm{~kg}$. Women with systemic medical disorders, operative delivery or other known pathology that predisposes to PTL like Polyhydramnios, PPROM, congenital anomalies, etc were not included in the study.

\section{Procedure}

Women fulfilling the inclusion criteria, both cases and controls were included in the study after taking a written informed consent. A detailed history including age, education, occupation, last menstrual period and prior pregnancy outcome was noted. Antenatal women included in the cases group who had threatened PTL (gestational age 28- 36 weeks) the gestational age was calculated from their last menstrual period or early trimester ultrasound. Total leucocyte count, differential count, urine culture and high vaginal swab culture were done as investigations to rule out general and genitourinary tract infection. Periodontal examination was done during their hospital stay.

In both cases and controls, for women who have delivered the gestational age at delivery was calculated from their last menstrual period. The birth weight of the baby was measured with an electronic weighing scale and recorded. Periodontal examination was done within three days postpartum.

Periodontal examination included Silness and Loe Plaque Index (PI), Muhlemann and Son Sulcus bleeding Index (SBI), Probing pocket depth (PD) and Clinical attachment level (CAL) was done.

\section{Silness and Loe plaque index (Pi)}

The plaque index was described by Silness P. and Loe H. in 1964. The measurement of the state of oral hygiene is based on both soft debris and mineralized deposits on the entire dentition or on selected teeth.

\section{Procedure}

The tooth was dried and examined visually. When no plaque was visible an explorer was used to test the surface. The explorer was passed across the tooth surface in the cervical third and near the entrance to the sulcus. Each of the four surfaces (buccal, lingual, mesial and 
distal) was given a score of 0-3. The index for the patient is obtained by summing up all the indices and dividing by the total number of teeth examined.

\section{Score Criteria}

0 - No plaque

1 - A film of plaque adhering to the free gingival margin and adjacent area of the tooth. The plaque may be seen in situ only after application of disclosing solution or by using the probe on the tooth surface.

2 - Moderate accumulation of soft deposits within the gingival pocket, or the tooth and gingival margin which can be seen with the naked eye.

3 - Abundance of soft matter within the gingival pocket and/or on the tooth and gingival margin.

\section{Sulcus bleeding index (SBI)}

SBI is an index for assessment of gingival bleeding, developed by Muhlemann H.R. and Son S. in 1971. The purpose of this index was to locate areas of gingival sulcus bleeding upon gentle probing and thus recognize and record the presence of early inflammatory gingival disease.

\section{Method}

Four gingival units were scored systematically for each tooth: the labial and lingual marginal gingivae ( $\mathrm{M}$ units) and the mesial and distal papillary gingivae ( $\mathrm{P}$ units). After 30 seconds of probing, scoring was done.

Score 0: Healthy appearance of $\mathrm{P}$ and M. No bleeding upon sulcus probing.

Score 1: Apparently healthy $\mathrm{P}$ and $\mathrm{M}$ showing no colour or contour changes and no swelling, but bleeding from sulcus on probing.

Score 2: Bleeding on probing and colour change caused by inflammation (reddening). No swelling or macroscopic edema.

Score 3: Bleeding on probing, change in colour, slight edematous swelling.

Score 4: 1) Bleeding on probing, change in colour, obvious swelling.

2) Bleeding on probing, obvious swelling.

Score 5: Spontaneous bleeding on probing, change in colour, marked swelling with or without ulceration.

Scores for the four units were totaled and divided by four.

\section{Probing pocket depth}

Periodontal pocket measurements were taken by inserting a periodontal probe, which was held parallel to the tooth, under the free gingival margin. After inserting and gently "walking" the probe's tip along the bottom of the pocket the level of attachment of the tooth's periodontal apparatus was measured accurately. The measurements were recorded at four to six points on each tooth. The measurement was made from the base of the sulcus, or pocket, to the free gingival margin.

\section{Clinical Attachment Level}

The clinical attachment refers to the estimated position of the structures that support the tooth as measured with a periodontal probe. The CAL provides an estimate of the stability of the tooth and the loss of bone support. The depth was measured from the CEJ (cemento-enamel junction) to the bottom of the gingival sulcus. It indicates the amount of attachment that has been lost.

According to WHO criterion for periodontitis is defined as Probing pocket depth $\geq 4 \mathrm{~mm}$ in at least 3 sites, in different teeth. CAL is assessed on various teeth at different sites. Based on CAL, periodontitis was classified as mild when CAL was 1-2 mm found in at least 3 sites and moderate periodontitis when CAL was 3$4 \mathrm{~mm}$ found in at least 3 sites. Severe periodontitis was diagnosed when $C A L \geq 5 \mathrm{~mm}$ and was found in at least 3 sites, in different teeth.

\section{Study Parameters}

The various demographic parameters were age occupation and education. The other study parameters were gestational age at delivery, birth weight of the newborn, Silness and Loe Plaque Index (PI), Muhlemann and Son Sulcus bleeding Index (SBI), Probing pocket depth (PD) and Clinical attachment level (CAL).

\section{RESULTS}

The present study was conducted in Mahatma Gandhi Medical College and Research Institute, Pondicherry, a tertiary care centre. It was done between February 2013 and June 2014. The study was carried out as per methodology after informed consent. The results were tabulated, analysed and shown in tables below.

Student $\mathrm{t}$ test (two tailed, independent) has been used to find the significance of study parameters on continuous scale between two groups (Inter group analysis) on metric parameters. Chi-square/ Fisher Exact test has been used to find the significance of study parameters on categorical scale between two or more groups. The Statistical software namely SAS 9.2, SPSS 15.0, Stata 10.1, MedCalc 9.0.1, Systat 12.0 and R environment ver.2.11.1 were used for the analysis of the data and Microsoft word and Excel have been used to generate graphs, tables, etc. 
Table 1: Demographic Parameters.

\begin{tabular}{|c|c|c|c|}
\hline Sr. No & Parameters analysed & Cases & Controls \\
\hline 1 & Age & $24.06 \pm 3.83$ & $24.16 \pm 3.41$ \\
\hline & Parity Primigravida & 67 & 52 \\
\hline 2 & Multigravida & 33 & 48 \\
\hline 3 & $\begin{array}{l}\text { Educational status } \\
\text { Primary school } \\
\text { Secondary school and above }\end{array}$ & $\begin{array}{l}0 \\
100\end{array}$ & $\begin{array}{l}3 \\
97\end{array}$ \\
\hline 4 & $\begin{array}{l}\text { Gestational age at inclusion } \\
<37 \text { weeks } \\
>37 \text { weeks }\end{array}$ & $\begin{array}{l}25 \\
75\end{array}$ & $\begin{array}{l}0 \\
100\end{array}$ \\
\hline 5 & Prior pregnancy abortions or preterm & $19 / 33$ & $\mathrm{P}=0.024^{*}$ \\
\hline 6 & $\begin{array}{l}\text { Mean gestational age at delivery } \\
<37 \text { weeks } \\
>37 \text { weeks }\end{array}$ & $\begin{array}{l}35 \mathrm{~W} 6 \mathrm{D} \pm 5 \mathrm{D} \\
38 \mathrm{~W} 6 \mathrm{D} \pm 7 \mathrm{D}\end{array}$ & $39 \mathrm{~W} 1 \mathrm{D} \pm 6 \mathrm{D}$ \\
\hline
\end{tabular}

Table 2: Periodontitis in relation to the gestational age.

\begin{tabular}{|lll|}
\hline $\begin{array}{l}\text { Gestational age } \\
\text { in weeks }\end{array}$ & Cases & Controls \\
\hline $\begin{array}{l}\text { Postnatal } \\
<37 \text { weeks }\end{array}$ & $\begin{array}{l}10 / 13 \\
(76.9 \%)\end{array}$ & 0 \\
\hline$>37$ weeks & $\begin{array}{l}66 / 75 \\
(88 \%)\end{array}$ & $76 / 100$ \\
& $10 / 12$ & 0 \\
\hline Antenatal & $(83.3 \%)$ & \\
\hline Total & 100 & 100 \\
\hline
\end{tabular}

Preterm birth and low birth weight are significantly associated with periodontitis with a $\mathrm{P}<0.001$

Table 3: Mean plaque index, bleeding index and evidence of periodontitis.

\begin{tabular}{|llll|}
\hline $\begin{array}{l}\text { Parameter } \\
\text { Analysed }\end{array}$ & Cases & Controls & \\
\hline $\begin{array}{l}\text { Mean plaque } \\
\text { index }\end{array}$ & $2.03 \pm 0.26$ & $1.96 \pm 0.19$ & $\mathrm{P}=0.035^{*}$ \\
\hline $\begin{array}{l}\text { Mean bleeding } \\
\text { index }\end{array}$ & $2.21 \pm 0.56$ & $1.99 \pm 0.63$ & $\mathrm{P}=0.009^{* *}$ \\
\hline $\begin{array}{l}\text { Periodontitis } \\
\quad \text { Mild }\end{array}$ & 21 & 49 & \\
$\quad \begin{array}{lll}\text { Moderate } \\
\text { Severe }\end{array}$ & 65 & 27 & $\mathrm{P}=0.001^{* *}$ \\
& 0 & 0 & \\
\hline
\end{tabular}

\section{DISCUSSION}

In the present study, the mean age of the participants in the two groups was $24.06 \pm 3.83$ and $24.16 \pm 3.41$ respectively (Table 1). The educational status of the patients was assessed in cases and controls. They were divided into four groups depending on their level of education as primary, secondary, higher secondary and graduation. 3\% among controls had their education only till primary level. All the women in the cases group had completed their primary education. $21 \%$ and $17 \%$ among case and control groups had their education till secondary level. 55\% in both groups had their educational level as higher secondary. $24 \%$ and $25 \%$ among cases and controls were graduates respectively. In the present study, $67 \%$ were primigravidae and $33 \%$ were multigravidae in the case group. In the control group, there were $52 \%$ and $48 \%$ of primigravidae and multigravidae respectively. On evaluating the previous pregnancy outcome 19 of 33 women in the cases and 10 of 48 women in the control group respectively had previous abortions or a preterm birth or both ( $\mathrm{p}$ value of 0.024 ).

Many other studies in the literature had considered prior abortions and previous preterm births as separate parameters. Gandhimadhi and Mythili in their study observed that $22.9 \%$ and $3.9 \%$ in the cases and controls respectively had previous abortions. ${ }^{10}$ Among the $22.9 \%$ of patients in cases, $20.2 \%$ and $2.7 \%$ had spontaneous and induced abortions respectively. All the $3.9 \%$ of patients with a prior history of abortion in the control group had an induced abortion. Alves and Ribeiro also observed that $15.1 \%$ and $17.5 \%$ of women in case and control groups respectively had previous spontaneous abortions. ${ }^{11}$ Incidence of spontaneous abortions in the case group was significant in all the above mentioned studies.

Gandhimadhi and Mythili in their study observed that $4.8 \%$ of patients in the case group had previous preterm birth and none of the patients in the control group had previous preterm birth which was not statistically significant. Mannem and Chava concluded that both prior abortions and prior preterm labour were not significantly associated with the incidence of periodontitis. ${ }^{8}$

In the present study, $15 \%$ and $38 \%$ of women in the case and control groups had previous term birth. Gandhimadhi and Mythili in their study observed that $11.4 \%$ of patients 
in the case group and all patients in the control group had previous term birth. Incidence of prior term birth was higher in the control group of both the studies. ${ }^{10}$

$75 \%$ and $100 \%$ of patients in cases and control group had delivered at a gestational age more than 37 weeks. The mean gestational age at delivery in the cases who delivered before 37 weeks was $35 \mathrm{~W} 6 \mathrm{D} \pm 5 \mathrm{D}$. The mean gestational age at delivery in the cases and controls who delivered after 37 weeks was $38 \mathrm{~W} 6 \mathrm{D} \pm 7 \quad \mathrm{D}$ and $39 \mathrm{~W} 1 \mathrm{D} \pm 6 \mathrm{D}$ respectively. Jacob and Nath in their study found that $48.2 \%$ and $14.1 \%$ in case and control groups respectively had preterm labour and $51.8 \%$ and $85.9 \%$ in case and control groups respectively delivered at gestational age more than 37 weeks (Table 2).

In the present study among the cases there were 25 women who had delivered preterm ( $<37$ weeks) and 75 women who had delivered at term ( $>37$ weeks). Among these 25 women who delivered preterm 12 were antenatal and 13 as postnatal. 10 of the 12 antenatal women had periodontitis $(83.3 \%)$ and 10 of the 13 postnatal women had periodontitis $(76.9 \%)$. Among the 75 women who had delivered at term but had low birth weight babies 66 had periodontitis (88\%). Among the controls, 76 of the 100 women included in the study had periodontitis (76\%). Comparing cases and controls, i.e. among women with either preterm labour or low birth weight babies, periodontitis was more significantly associated with cases and this was statistically significant $(\mathrm{P}<0.001)$.

Jacob and Nath found that periodontitis was more frequently associated with cases than controls $(52.9 \%$ vs $27.6 \%$ ). Alves and Ribeiro in their study found that the incidence of periodontitis was more associated with cases than controls $(84.2 \%$ vs $37.5 \%)$ and this was statistically significant with a p value 0.00114. Gandhimadhi and Mythili found that the extent and severity of periodontitis was more significant among cases than controls and this was also statistically significant. Yen-Li Wang et al in their study found a significant number of women who delivered preterm belonged to the periodontitis group $(11 / 22)$ when compared with healthy women or those who had only gingivitis. ${ }^{12}$

In the present study the mean birth weight distribution was $2298.76 \pm 228.95 \mathrm{~g}$ and $2948.59 \pm 312.00 \mathrm{~g}$ in the case and control groups respectively. Mannem and Chava in their study observed that the mean birth weight was $2.01 \pm 0.36 \mathrm{~kg}$ and $2.87 \pm 0.32 \mathrm{~kg}$ in the case and control groups respectively. Jacob and Nath in their study observed that the mean birth weight was $1999.7 \pm 303.0 \mathrm{~g}$ and $2785.6 \pm 321.6 \mathrm{~g}$ in the case and control groups respectively. In the present study and in all the other studies birth weight is an inclusion criteria so they are comparable.

In the present study, $12 \%$ of women in the case group were antenatal with threatened preterm labour. Among those 12 women, $50 \%$ had genitourinary tract infection.
Gandhimadhi and Mythili in their study observed that $11 \%$ and $11.8 \%$ in the case and control groups had genitourinary tract infection. In Jacob and Nath study, $6.47 \%$ and $4.7 \%$ in case and control groups had genital tract infection. Alves and Ribeiro in their study observed that $36.8 \%$ and $35 \%$ of women in group 1 and group 2 respectively had urinary tract infection. In all of the above studies, genitourinary tract infection was associated with preterm labour and low birth weight, though not statistically significant.

Apart from age, educational status and prior pregnancy outcomes, Jacob and Nath in their study had included other factors like socioeconomic status, consanguinity, smokeless tobacco, number of antenatal visits, intake of iron and calcium supplements, anemia and arterial hypertension. They found that these factors were not significantly associated with low birth weight. Similarly Gandhimadhi and Mythili in their study included other characteristics like blood group, Rhesus factor, hypertension, tobacco or alcohol and the onset of prenatal care. They found that these factors were also not significantly associated with preterm low birth weight. Alves and Ribeiro also included other factors like height, anemia, hypertension and diabetes. They also concluded that these factors were not significantly associated with preterm low birth weight.

In the present study, the mean plaque indices for the case and control groups were 2.03 \pm 0.26 and $1.96 \pm 0.19$ respectively (Table 3 ). Comparing the two groups, the mean plaque index of the case group was significantly more than the control group. This was also statistically significant with a $\mathrm{p}$ value of 0.035 . Mannem and Chava in their study observed that the mean plaque index for the case and control groups were $1.21 \pm 0.56$ and $0.63 \pm 0.31$ respectively. The mean plaque index is higher in case group and this was also statistically significant ( $\mathrm{p}$ value < 0.0001). Studies conducted by Gandhimadhi and Mythili, Jacob and Nath, Nabet et al and Alves and Ribeiro did not include plaque index as a factor to assess periodontitis.

In the present study, the mean bleeding indexes for the case and control groups were 2.21 \pm 0.56 and $1.99 \pm 0.63$ respectively (Table 3 ). Comparing the two groups the mean bleeding index was significantly lower in the control group. This was also statistically significant with a $p$ value of 0.009 . Mannem and Chava in their study observed that the mean bleeding index for the case and control groups were $2.08 \pm 0.62$ and $1.52 \pm 0.61$ respectively. Higher bleeding Index was more associated with cases and was statistically significant.Gandhimadhi and Mythili in their study have assessed the gingival bleeding index with Ainamo and Bay scoring. In their study the bleeding index was not statistically significant. Jacob and Nath and Nabet et al did not include bleeding index as a parameter of periodontitis in their study. 
In the present study, WHO criterion of periodontitis was used. With this criterion, evidence of periodontitis was seen in $86 \%$ of cases and $76 \%$ of controls respectively. Using the same criteria, Jacob and Nath in their study found that evidence of periodontitis was present in $52.94 \%$ and $27.64 \%$ of cases and controls respectively. Mannem and Chava considered periodontitis to be present when the $\mathrm{PD}$ was $\geq 4 \mathrm{~mm}$ and the CAL was $\geq$ $3 \mathrm{~mm}$ at the same site in at least four teeth. Evidence of periodontitis was present in $84.6 \%$ of cases and only in $3.8 \%$ of control group. Incidence of periodontitis was significantly more among the cases in the present study as observed in Mannem and Chava study.

Nabet et al in his study, classified periodontitis as localized periodontitis when $\mathrm{PD} \geq 4 \mathrm{~mm}$ and $\mathrm{CAL} \geq 3 \mathrm{~mm}$ at the same site on 2 or 3 teeth and as generalized periodontitis when $\mathrm{PD} \geq 4 \mathrm{~mm}$ and $\mathrm{CAL} \geq 3 \mathrm{~mm}$ at the same site on four or more teeth ${ }^{13}$. They found that $11.6 \%$ and $10.8 \%$ of cases and controls respectively had localized periodontitis. $13.4 \%$ and $10.8 \%$ of cases and controls respectively had generalized periodontitis. Gandhimadhi and Mythili in their study found that the mean probing pocket depth in the case and control groups was $3.12 \pm 1.02$ and $2.83 \pm 1.00$ respectively which was statistically significant with a $\mathrm{p}$ value of 0.03 . Extent and severity of attachment loss which was derived from the clinical attachment level was also statistically significant.Alves and Ribeiro assessed periodontal status with modified Periodontal Screening and Recording criteria and found that the prevalence of periodontitis was higher in the case group.

Based on CAL, periodontitis was classified as mild, moderate and severe. Mild periodontitis was considered to be present when CAL was 1-2 mm found in at least 3 sites and moderate periodontitis when CAL was 3-4 mm found in at least 3 sites. Severe periodontitis was diagnosed when $\mathrm{CAL} \geq 5 \mathrm{~mm}$ and was found in at least 3 sites in different teeth. In the present study, $21 \%$ and $49 \%$ of patients among the case and control groups had evidence of mild periodontitis (Table 3). $65 \%$ and $27 \%$ of patients among the case and control groups had evidence of moderate periodontitis. Severe periodontitis was not seen in either cases or controls. In Jacob and Nath study, $38.82 \%$ and $23.52 \%$ of patients among the case and control groups had evidence of mild periodontitis, $8.82 \%$ and $4.11 \%$ had evidence of moderate periodontitis and $5.29 \%$ of patients among the case group had evidence of severe periodontitis. In the present study, moderate periodontitis was found in significant number of cases and was statistically significant with a $p$ value of $<0.001$. This suggests that there exists a strong association between moderate periodontitis and preterm labour and low birth weight.

\section{CONCLUSIONS}

The etiology of preterm birth and low birth weight are multifactorial. Periodontitis is one of the risk factors for preterm labour and low birth weight. In the present study, periodontal factors like Plaque Index (PI), Sulcus bleeding Index (SBI), Probing pocket depth (PD), and Clinical attachment level (CAL) were analyzed. Plaque index was significantly associated with preterm labour and lowbirth weight. Bleeding index was also significantly associated with preterm labour and low birth weight. Evidence of periodontitis was seen among more number of cases and was significantly associated with preterm labour and low birth weight. There was a significant association between moderate periodontitis and preterm labour and low birth weight.

\section{Recommendation}

This study suggests that further research involving larger sample size or large population based studies are needed to prove periodontitis as an individual risk factor for preterm labour and low birth weight. Periodontitis being a modifiable risk factor, dental care should be integrated as a part of routine prenatal care.

\section{Funding: No funding sources \\ Conflict of interest: None declared \\ Ethical approval: The study was approved by the Institutional Ethics Committee}

\section{REFERENCES}

1. WHO fact sheet $\mathrm{N} * 363$ updated November 2014

2. Cunningham FG, Leveno KJ, Bloom SL, Hauth JC, Rouse DJ, Spong CY. Williams Obstetrics. 23rd ed. United States of America: McGraw-Hill Companies; 2010;804-27.

3. Paquette DW. The periodontal infection-systemic disease link: a review of the truth or myth. J Int Acad Periodontol 2002;4:101.19.

4. Damare SM, Wells S, Offenbacher S. Eicosanoids in periodontal diseases: potential for systemic involvement. Adv Exp Med Biol. 1997;123:23-35.

5. Offenbacher S. Periodontal diseases: pathogenesis. Ann Periodontol. 1996;11:821-78.

6. López NJ, Da Silva I, Ipinza J, Gutiérrez J. Periodontal therapy reduces the rate of preterm low birth weight in women with pregnancy associated gingivitis. J Periodontol. 2005;76(11 Suppl):211453.

7. Gundala R, Chava VK. Effect of lifestyle, education and socioeconomic status on periodontal health. Contemp Clin Dent. 2010;11:23-6.

8. Mannem S, Chava VK. The relationship between maternal periodontitis andpreterm low birth weight: A Case-Control Study. Contemp Clin Dent. 2011;2(2):88-93.

9. Jacob PS, Nath S. Periodontitis among poor rural Indian mothers increases the risk of low birth weight babies: a hospital-based case control study. J Periodontal Implant Sci. 2014;44(2):85-93. 
10. Gandhimadhi and Mythili R. Periodontal infection as a risk factor for pretermlow birth weight. J Indian soc periodontol. 2010;14(2):114-20.

11. Alves RT, Ribeiro RA. Relationship between maternal periodontal disease and birth of preterm low birth weight babies. Braz Oral Res. 2006;20(4):318-23.

12. Wang YL, Liou JD, Pan WL. Association between maternal periodontal disease and preterm delivery and low birth weight. Taiwanese Journal of Obstetrics \& Gynecology. 2013;521:71-6.
13. Nabet C, Lelong N, Colombier ML, Sixou M, Musset AM, Goffinet F, et al. Epipap Group. Maternal periodontitis and the causes of preterm birth: the case-control Epipap study. J Clin Periodontol. 2010;371:37-45.

Cite this article as: Saranya C, Sendhil Coumary A, Kumar S, John LB, Ghose S. Periodontitis as a risk factor for preterm labour and low birth weight among pregnant women attending a tertiary care teaching hospital. Int J Reprod Contracept Obstet Gynecol 2015;4:1804-10. 